\title{
Customer Satisfaction as a Quality Factor in Geriatric Rehabilitation
}

\author{
Mauro Colombo ${ }^{*}, 1,2$, Antonio Guaita ${ }^{1,2}$, Maria Cottino ${ }^{1}$, Marco Cairati ${ }^{1}$, Danila Ferrari ${ }^{1}$, \\ Giorgio Previderè ${ }^{1}$, Giuseppe Procino ${ }^{1}$, Maria Carla Gandolfi ${ }^{1}$, Rosaria Tararà ${ }^{1}$ and \\ Angela Mercanti ${ }^{1}$ \\ ${ }^{1}$ Geriatric Institute Camillo Golgi, Abbiategrasso, Milan, Italy \\ ${ }^{2}$ Golgi Cenci Foundation, Abbiategrasso, Milan, Italy
}

\begin{abstract}
Customer satisfaction is relevant for geriatric rehabilitation, besides objective outcomes. We aimed at measuring customer satisfaction at discharge from our rehabilitative wards, and at singling out its predictive factors. We studied 506 elderly patients, aged $78 \pm 8$ years. Satisfaction at discharge scored high in all 4-levels graded items of a questionnaire surveying perception of patient improvement, quality of rehabilitative treatment, physicians' and nurses' intervention, personal care, lodging quality, goodness of information got. Mean overall rating (scoring 0 to 10) of the rehabilitative stay was $9.2 \pm 2.1$, median and mode were 10. Rating correlated with: relative functional gain $(\mathrm{r}=0.23, \mathrm{p}<.000)$, absolute Barthel Index total score at discharge $(r=0.18, \mathrm{p}<.000)$, net gain in Barthel Index total score at discharge $(\mathrm{r}=0.1, \mathrm{p}=$ $0.021)$, and improvement in CIRS Severity Index $(r=0.9, p=0.043)$. Relative functional gain was the only variable predictive of rating that was retained by stepwise multiple regressions $(\mathrm{p}<.000)$.
\end{abstract}

Keywords: Customer satisfaction, geriatric rehabilitation, functional gain.

\section{INTRODUCTION}

The body of evidence favoring geriatric rehabilitation is growing incessantly [1]. Traditional outcomes of geriatric rehabilitation include: 1) functional improvement, 2) clinical stabilization, and 3) getting back home. Such aims can be pursued to somewhat different extents and at varying degrees of combinations [2]. Yet, it matters of objective outcomes only. Subjective aspects are getting increasing relevance [35]. Customer satisfaction is a concept centred on the vision of the patient as a "user-client", in the "total quality" perspective [www.eoq.org accessed 1-12-2008]. Only the client's perspective (by the patient her/him-self, or by a valid proxy) provides a full comprehension of the effects of disease(s) and treatment(s) on the patient [5]. Customer satisfaction then stands besides objective outcomes of geriatric rehabilitation. Therefore, we aimed at estimating customer satisfaction at discharge from our rehabilitation wards (by the patient her/him-self, or by a proxy) and at picking out possible predictive factors.

\section{MATERIALS AND METHODS}

\section{Outcome Measures}

In order to measure customer satisfaction, we built an onpurpose questionnaire, using few simple words easily understandable also by old persons with low formal education. Such questionnaire taps the following items: patient improvement, perceived quality of rehabilitative treatment, physicians' and nurses' intervention, personal care, lodging

*Address correspondence to this author at the Geriatric Institute Camillo Golgi, 11 piazza Golgi, Abbiategrasso, Milan 20081, Italy; Tel: 0039-02948521; Fax: 0039-02-94852909; E-mail: m.colombo@golgiredaelli.it quality, goodness of information purchased. Customer feelings are which graded on four levels: "very dissatisfied", "dissatisfied", "satisfied", "very satisfied", not allowing for neutral answers, as already performed in rehabilitative settings [6]. A grade from zero to ten synthesized the overall judgment on the rehabilitative stay. Customer expectation may vary between items: yet, we decided not to load our items, as a preliminary survey concluded that our clients had top expectations in every care items. Once refined, the questionnaire was offered to all patients and / or relatives, close to discharge; yet, many did not respond.

\section{Explanatory Measures}

Functional status was assessed at entry and at discharge by the Barthel Index (BI), as revised by Shah - in the Italian translation validated by one of author (M.C.): the BI is the most widely used and robust scale for dependence [7, 8]. Loaded scores in ten basic activities of daily living are summed to a potential total score of 100 . Overall functional outcome was measured also as \% functional gain relative to the rehabilitative potential, according to the formula: [(BI total score at discharge - BI total score at entry) *100] / (100 - BI total score at entry). Clinical status was assessed through the Cumulative Illness Rating Scale (CIRS) by comorbidity and severity indexes, both at entry and at discharge [9]. Basic cognitive function was assessed by the Mini Mental Status Examination (MMSE) [10].

\section{Setting}

A rehabilitation ward whose two units host forty inpatients each; the staff consisted of forty-two nurse-aids, twelve registered nurses, two head nurses, eleven physiotherapists, two nurse-aids committed to the gym, and six physicians. 
Table 1. Patients' Characteristics at Admission and Respective Modifications at Discharge

\begin{tabular}{|c|c|c|c|}
\hline Variable & Admission Score: Mean (SD) & Difference at Discharge: Mean (SD) $^{\mathbf{a}}$ & $21.4(14.7)$ \\
\hline \hline Barthel Index (BI) total score & $56.5(25)$ & $-0.17(0.19)$ & $<.000$ \\
\hline CIRS severity index & $2.1(1.4)$ & $-1(1.2)$ & $<.000$ \\
\hline CIRS comorbidity index & $4.6(2.1)$ & $2.4 / 30(3)$ & $<.000$ \\
\hline MMSE & $21.5 / 30(6.9)$ & $<.000$ \\
\hline
\end{tabular}

Abbreviations

CIRS: Cumulative Illness Rating Scale; MMSE: Mini Mental Status Examination.

Notes

${ }^{\mathrm{a}}$ By paired t-test

\section{Statistical Analysis}

Descriptive analysis, measures of associations (by crosstabulations), group comparisons (by paired parametric as well as non-parametric tests, as appropriate), bivariate correlations and multiple regression were conducted with SPSS software for Windows, release 11 (SPSS, Chicago, IL, USA).

\section{RESULTS}

We studied 506 patients admitted in our rehabilitation wards, who filled the questionnaire. Half of them came from their home and half from nearby referring hospitals, because of a variety of typical geriatric diagnosis or syndromes. Main problems at entry were disability following fractures, hemiplegia, joint replacement, but they comprised also deconditioning due heart failure, parkinsonism, vascular peripheral disease, and convalescence or immobilization syndromes after medical or surgical hospital stays, with related complications such as pressure sores or dysphagia. Two patients out of three were female; their mean age was 78 years (Standard Deviation: $\mathrm{SD}=8$ ). Socio-demographic features and relevant health status / frailty variables were reported by a simple checklist: $40 \%$ lived alone, $14 \%$ had communications impairments, $10 \%$ needed some arrangement to be fed.

Non-responders inpatients were older, more functionally and clinically impaired (both at admission and at discharge), had more frequent troubles with communication and feeding, had more problems with pressure sores (both at admission and at discharge); they had also less efficient gains in severity and comorbidity and marginally lower MMSE at discharge; they were less frequently discharged to home. No statistically significant differences were found between respondents and non-respondents as for age, sex, living together, cognitive level at admission, absolute functional and cognitive gains, and length of stay.

Two set of results will be shown: the first set (I) will focus on overall geriatric rehabilitation outcomes - relative to the traditional aims of geriatric rehabilitation, and other contextual information, the second set (II) will pertain specifically satisfaction outcomes.

(I) $89,7 \%$ of patients were discharged to home. Mean length of stay was 43.7 days ( $\mathrm{SD}=16.3)$. Patients' features and respective modifications at discharge are shown in Table 1.

Entry mean Barthel Index total score corresponded to a moderate - severe dependence; at discharge, functional gain achieved a mild dependence level, through the fulfillment of $58.6 \%(\mathrm{SD}=31.8 \%)$ of the rehabilitative potential. Also clinical and cognitive indicators averaged significant gains. $17.2 \%$ of patients had one or more pressure sores stage $\geq 2$ (according to European Pressure Ulcer Advisory Panel (EPUAP) grading) at entry, who became $6.8 \%$ at discharge $(\mathrm{p}<.000$ by both Chi-square and Kendall's tau-b tests, across all stages); also the number of pressure sores per patient - stage $\geq 2$ EPUAP - decreased significantly $(\mathrm{p}<.000$ by Wilcoxon test).

(II) Satisfaction scored high in all 4-levels graded items of a questionnaire surveying perception of patient improvement, quality of rehabilitative treatment, physicians' and nurses' intervention, personal care, lodging quality, goodness of information purchased. $91.3 \%$ of clients perceived an improvement (of which, $53.9 \%$ "very improved"). Satisfaction ranked top for $85 \%$ of physicians' work. Also perceived quality of rehabilitative treatment, physicians' and nurses' intervention, personal care, lodging quality, goodness of information purchased achieved almost a $100 \%$ of positive appreciations, albeit less top ranking than the former judgment. The overall rating (scoring 0 to 10 ) of the rehabilitative stay achieved a mean of $9.2(\mathrm{SD}=2.1)$, and a mode and median of 10. Details of overall rating are shown in Table 2.

Table 2. Satisfaction Overall Rating Score by Different Rater

\begin{tabular}{l|c|c|c|c|}
\hline Rater & Mean (SD) & Rater & Mean (SD) & $\mathbf{p}^{\mathbf{a}}$ \\
\hline \hline Patients & $9.4(0.9)$ & Proxies & $9(1)$ & $<.000$ \\
\hline Males & $9.4(0.9)$ & Females & $9.1(1)$ & $<.000$ \\
\hline
\end{tabular}

Bivariate correlations with rating, in decreasing order of significance, are shown in Table $\mathbf{3}$.

\section{DISCUSSION}

Our data report highly perceived satisfaction and highlight the role of functional gain as a mainstay for customer satisfaction [11]. These result substantially agree with the literature, also in specific geriatric rehabilitative settings such as orthopedic and neurologic contexts. Some authors indeed have investigated satisfaction with community participation. Ostir et al., for example, have found that gains in functional status were significantly associated with greater satisfaction with community participation, at 80 to 180 day 
Table 3. Statistically Significant Bivariate Correlations of Satisfaction Overall Rating Score

\begin{tabular}{|c|c|c|}
\hline Variable & $\mathbf{r}^{\mathbf{a}}$ & $\mathbf{p}^{\mathbf{b}}$ \\
\hline Relative functional gain & 0.23 & $<.000$ \\
\hline Absolute Barthel Index total score at discharge & 0.18 & $<.000$ \\
\hline Net gain in Barthel Index total score at discharge & 0.1 & 0.021 \\
\hline Improvement in CIRS Severity Index & 0.09 & 0.043 \\
\hline \multicolumn{3}{|c|}{$\begin{array}{l}\text { Notes } \\
{ }^{a} \text { Pearson Correlation. } \\
\text { b 2-tailed significance. } \\
\text { Relative functional gain was the only variable predictive of rating that was retained by } \\
\text { stepwise multiple regressions }(\mathrm{p}<.000) \text {. }\end{array}$} \\
\hline
\end{tabular}

follow-up after medical rehabilitation for orthopedic impairments [12]. Their overall levels of satisfaction $(87 \%$ were very or somewhat satisfied) approach ours. In a similar setting, functional as well as demographic variables were identified as predictors of satisfaction, in patients with orthopedic impairments. A logistic regression model correctly classified $94.9 \%$ of the patients, relying on five variables. Specifically, discharge Functional Impairment Measure motor subscale ratings were significantly associated with increased satisfaction in patients with joint replacements and lower-extremity fractures. The sample investigated by Mancuso et al. was a little younger than our (mean age $=73$, $\mathrm{SD}=11.8$ years), yet gender mix was quite similar (mostly females) [13]. Patient satisfaction 3 to 6 months after rehabilitation discharge for stroke was affected by change in functional status, and by the source of information: satisfaction rating differed whether the response was collected from patient or proxy, as in our sample [14].

We are aware of limitations in the present study. The first limitation to mention is the low proportion of variance in satisfaction rating explained by our multiple stepwise regression model (adjusted R squared $=0,053$ ). Indeed customer satisfaction is influenced by a host of factors - included an enhanced patient orientation, so that patient satisfaction can be increased during inpatient rehabilitation after total hip and total knee arthroplasty even while the functional change from admission to discharge decreases [15]. Another important factor we didn't yet measure at the time of the present study, which can influence patient satisfaction, is pain. In persons with stroke, for example, high pain rating scores, were significantly associated with lower satisfaction with community participation [16]. Besides neurological settings, also better postoperative pain control may improve patients' levels of satisfaction. Postoperative pain from hip or knee replacement is associated with reduced satisfaction with medical rehabilitation, some 90 days after discharge [17]. Good patient education is shown to be effective in terms of improving patient expectations and also associated with an early functional recovery after surgery [18]. More, length of stay may influence customer appreciation with medical rehabilitation. Satisfaction rating in our study was not related with the length of the rehabilitative stay, at variance with Grissom and Dunagan [15]. Other enquiries on customer satisfaction in rehabilitation settings are weak too. In Veterans Affairs medical centres, post-acute stroke guideline compliance is associated with greater patient satisfaction. In their multivariate analysis of the hospital satisfaction dimension, Reker's et al. model got an R squared $=0,15$ [6].

\section{CONCLUSIONS}

In conclusion, we want to highlight two issues:

1. Patient satisfaction is correlated to a reasonable outcome: relative functional gains, according to the Montebello Rehabilitation Factor Score [19].

2. it is worthwhile to mention that customer satisfaction goes together with caregivers' one: intriguing models based on sound geriatric education of the staff, by team working in coordinated modules, get all at once relevant clinical outcomes and satisfaction [20].

\section{ACKNOWLEDGEMENT}

We are grateful to the whole staff of Camillo Golgi Geriatric Institute.

\section{REFERENCES}

[1] Bellelli G, Guerini F, Bianchetti A, De Palma D, Ther P, Trabucchi M. Medical comorbidity and complexity of the rehabilitative procedures for older patients with functional impairments. J Am Geriatr Soc 2002; 50: 2095-6.

[2] Colombo M, Guaita A, Cottino M, Previderè G, Ferrari D, Vitali S The impact of cognitive impairment on the rehabilitation process in geriatrics. Arch Gerontol Geriatr Suppl 2004; 9: 85-92.

[3] Ostir GV, Smith PM, Smith D, Ottenbacher J. Functional status and satisfaction with community participation in persons with stroke following medical rehabilitation. Aging Clin Exp Res 2005; 17: 35 41.

[4] Tulsky DS, Rosenthal M. Quality of life measurement in rehabilitation medicine: building an agenda for the future. Arch Phys Med Rehabil 2002; 83 (Suppl 2): S1-3.

[5] Cella D, Nowinski CJ. Measuring quality of life in chronic illness: the functional assessment of chronic illness therapy measurement system. Arch Phys Med Rehabil 2002; 83 (Suppl 2): S10-7.

[6] Reker DM, Duncan PW, Horner RD, et al. Postacute stroke guideline compliance is associated with greater patient satisfaction. Arch Phys Med Rehabil 2002; 83: 750-6.

[7] Shah S, Vanclay F, Cooper B. Improving the sensitivity of the Barthel Index for stroke rehabilitation. J Clin Epidemiol 1989; 42: 703-9.

[8] Lazaridis EN, Rudberg MA, Furner SE, Cassel CK. Do activities of daily living have a hierarchical structure ? An analysis using the longitudinal study of aging. J Gerontol Med Sci 1994; 49: M47M51

[9] Parmalee PA, Thuras PD, Katz IR, Lawton MP. Validation of the cumulative illness rating scale in a geriatric residential population. J Am Geriatr Soc 1995; 43: 130-7.

[10] Folstein MF, Folstein SE, McHugh PR. Mini-Mental State : a practical method for grading the cognitive state of patients for the clinician. J Pshychiatr Res 1975; 12: 189-98.

[11] Studenski S, Duncan PM. Measuring rehabilitation outcomes. Clin Geriatr Med 1993; 9: 823-30.

[12] Ostir GV, Smith PM, Smith D, Rice JL, Ottenbacher J. Orthopedic impairment after medical rehabilitation: functional performance and satisfaction with community participation. Am J Phys Med Rehabil 2005; 84: 763-9.

[13] Mancuso M, Smith P, Illig S, et al. Satisfaction with medical rehabilitation in patients with orthopedic impairment. Arch Phys Med Rehabil 2003; 84: 1343-9.

[14] Tooth LR, Ottenbacher KJ, Smith PM, et al. Effect of functional gain on satisfaction with medical rehabilitation after stroke. Am J Phys Med Rehabil 2003; 82: 692-9.

[15] Grissom SP, Dunagan L. Improved satisfaction during inpatient rehabilitation after hip and knee arthroplasty: a retrospective analysis. Am J Phys Med Rehabil 2001; 80: 798-803.

[16] Ostir GV, Smith PM, Smith D, Berges IM, Ottenbacher KJ. The influence of perceived pain on satisfaction with community participation after hospital discharge. Arch Phys Med Rehabil 2005; 86: 2095-100. 
[17] Bergés IM, Ottenbacher KJ, Smith PM, Smith D, Ostir GV. Perceived pain and satisfaction with medical rehabilitation after hospital discharge. Clin Rehabil 2006; 20: 724-30.

[18] Fortina M, Carta S, Gambera D, Crainz E, Ferrata P, Maniscalco P. Recovery of physical function and patient's satisfaction after total hip replacement (THR) surgery supported by a tailored guide-book. Acta Biomed 2005; 76: 152-6.
[19] Heruti RJ, Lusky A, Dankner R, et al. Rehabilitation outcome of elderly patients after a first stroke: effect of cognitive status at admission on the functional outcome. Arch Phys Med Rehabil 2002; 83: 742-9.

[20] Tucker D, Bechtel G, Quartana C, et al. The OASIS program: redesigning hospital care for older adults. Geriatr Nurs 2006; 27 : 112-7.

(c) Colombo et al.; Licensee Bentham Open.

This is an open access article licensed under the terms of the Creative Commons Attribution Non-Commercial License (http://creativecommons.org/licenses/by$\mathrm{nc} / 3.0 /$ ) which permits unrestricted, non-commercial use, distribution and reproduction in any medium, provided the work is properly cited. 